\title{
Heat Transport Improvement and Three-Dimensional Rotating Cone Flow of Hybrid-Based Nanofluid
}

\author{
Azad Hussain, ${ }^{1}$ Qusain Haider $(D),{ }^{1}$ Aysha Rehman $\left(D^{1},{ }^{1}\right.$ M. Y. Malik $\left(D,{ }^{2}\right.$ Sohail Nadeem (D), ${ }^{3}$ \\ and Shafiq Hussain ${ }^{4}$ \\ ${ }^{1}$ Department of Mathematics, University of Gujrat, Gujrat 50700, Pakistan \\ ${ }^{2}$ Department of Mathematics, College of Sciences, King Khalid University, Abha 61413, Saudi Arabia \\ ${ }^{3}$ Department of Mathematics, Quaid-I-Azam University, Islamabad 44000, Pakistan \\ ${ }^{4}$ Department of Computer Science, University of Sahiwal, Sahiwal, Pakistan
}

Correspondence should be addressed to Qusain Haider; qusain.haider336@gmail.com

Received 15 December 2020; Accepted 28 September 2021; Published 27 October 2021

Academic Editor: Fateh Mebarek-Oudina

Copyright ( $\odot 2021$ Azad Hussain et al. This is an open access article distributed under the Creative Commons Attribution License, which permits unrestricted use, distribution, and reproduction in any medium, provided the original work is properly cited.

\begin{abstract}
The current research aims to study the mixed convection of a hybrid-based nanofluid consisting of ethylene glycol-water, copper (II) oxide $(\mathrm{CuO})$ and titanium dioxide $\left(\mathrm{TiO}_{2}\right)$ in a vertical cone. A hybrid base blend model is used to examine the nanofluid's hydrostatic and thermal behaviors over a diverse range of Reynolds numbers. The application of mixed nanoparticles rather than simple nanoparticles is one of the most imperative things in increasing the heat flow of the fluids. To test such a flow sector, for the very first time, a hybrid-based mixture model was introduced. Also, the mixture framework is a single-phase model formulation, which was used extensively for heat transfer with nanofluids. Comparison of computed values with the experimental values is presented between two models (i.e., the model of a mixture with the model of a single-phase). The natural convection within the liquid phase of phase change material is considered through the liquid fraction dependence of the thermal conductivity. The predicted results of the current model are also compared with the literature; for numerical results, the bvp4c algorithm is used to quantify the effects of nanoparticle volume fraction diffusion on the continuity, momentum, and energy equations using the viscous model for convective heat transfer in nanofluids. Expressions for velocity and temperature fields are presented. Also, the expressions for skin frictions, shear strain, and Nusselt number are obtained. The effects of involved physical parameters (e.g., Prandtl number, angular velocity ratio, buoyancy ratio, and unsteady parameter) are examined through graphs and tables.
\end{abstract}

\section{Introduction}

Nanofluid is the mixture of hard nanoparticles with the base fluid. The study of nanofluid is of huge interest for the evaluation of increasing thermal conductivity, In the engineering, cooling is important, such as the cooling of nano-electromechanical systems and semiconductors. The convection of nanofluids flow in nanowires such as microchannels and microtubes is mandatory to use nanofluids for these low-scale cooling techniques. Nanofluids are served in related works with single-phase heterogeneous fluids (whereas the nanoparticles are consistently distributed in base fluids). Free convection is critical in thermal engineering in nanofluid within enclosures because rising heat flow is a significant problem for energy efficiency. The first attempts to improve heat transport using nanofluid. They simulated the heat transfer features of nanofluids in a two-dimensional insertion and originate that the heat transfer rate dramatically increases with postponed nanoparticles at every Grashof value. Elaziz and Marin [1] investigated one significant feature of theory, and it does not account for thermal energy dissipation. We discover a method for dealing with elastic interactions that do not take into account energy dissipation caused by heat sources and body forces. Remote as literature analysis is revised, 
[2-12] scholars are doing notable nanofluid work. The analysis of heat transmission and nanofluid flow is an important unsolidified rheology issue. Experimenting on $\mathrm{Cu}$-water nanofluid rheology, in which we noticed the conduct of a shear-thinning fluid obtained by Chang et al., [13] Santra et al. [14] introduced the forced conduction of $\mathrm{Cu}$-water in Newtonian and non-Newtonian fluids in a channel. Das et al. [15] extended Aziz's attempt by looking at the Buongiorno fluid method for nanofluid flow. Xuan and $\mathrm{Li}$ [16] explored $\mathrm{Cu}$-water nanofluid flow characteristics. Infrared photons are visible; sunlight or infrared and illumination are shown by the material nature produced from those radiations. Based on the way solar energy is collected and transmitted or transformed into solar power, energy sources and their technologies are mostly known as either active solar or inactive solar. Blackbody radioactivity is the radiation of electromagnetic waves from a superficial that exceeds absolute zero. In several practical applications, heat transport occurs via a porous medium flow. These inspections cover a wide range of fields of science and engineering, mainly grain storage, chemical hydrogen reactors, dampness movement by air-filled rubber protection, and much more. The efficiency of common base fluid thermal systems is relatively low. Suspending metallic nanoparticles in the sordid fluid is a recent way to improve the efficiency of those systems. Sheikholeslami et al. [17] investigated the free convection warmth transfer in a concentration halo between warm four-sided and heated curve cylinders in the non-attendance of the magnetic field. Kandelousi [18] investigated the consequence on ferrofluid flow of especially variable magnetic fields by considering the constant heat flux endpoint state. Sheikholeslami et al. [19-21] examined nanofluid flow alongside convective heat transfer through a different geometry. The fluid flows including chemical reaction has wide range in the processes of extrusion, refrigeration, and polymer industries. Under GN electromagnetic theory, Abd-Elaziz et al. [1] demonstrated the effect of Thomson and initial stress in a thermo-porous elastic solid. Vlase et al. [22] looked into the motion equation for a versatile one-dimensional element used in a multibody system's dynamical analysis. Malik et al. [23] proposed the idea of an incompressible fluid past MHD natural reaction over a heat-producing porous layer. The electrically transmitting non-Newtonian fluids can be used as a refrigeration liquid because their flow can be controlled by the outdoor magnetic field, which to some degree controls the heat transfer. Its usage of magnetic fields that impact heat preoccupation/generation system has several engineering applications, like crystallization and bottling of copper wires by dragging continuous polymers through inactive fluid [24-29].

Shirejini et al. [30] used a nanofluid and a gyratory scheme to restore the heat transfer rate after a decrease. Turkyilmazoglu [31-33] investigated the thermal broadcast of an electrically conductive fluid over a rotating infinite disk. Digital devices for stowage, rotating equipment, thermal energy generation systems, electrode material, geothermic industry, gas turbines, biological courses, and different types of medical equipment are examples of applications of such problems. Turkyilmazoglu investigated fluid stream and heat allocation on a rotating disk that was traveling vertically. A spinning cone induces warmth transfer and enables flow in a quiescent liquid. Kumar et al. [34] used a finite element method to research the randomness production of a nanofluid containing copper and aluminum oxide nanoparticles in the spaces between two coaxial spinning disks.

The above studies indicate that no attempt has been complete to analyze the $3 \mathrm{D}$ hybrid nanofluid flow model around the cone as poignant or immobile under fluid control. The effect of copper oxide $(\mathrm{CuO})$ and titanium dioxide $\left(\mathrm{TiO}_{2}\right)$ nanoparticles on the thermal performance properties of ethylene glycol-water is investigated in this study, which has an extensive scientific and technological value. The second significance is to build on the principle of Refs. [35-37] which also contain the most important studies about the current model. In the case of counterrotating, create a mathematical model for rotating cones that are called moving or stationary. The flow reckonings are reduced to an ordinary scheme, and then bvp $4 \mathrm{c}$ is used to solve them. Figures illustrate the effects of corporeal relevant variable quantity on velocity and temperature. Superficial grind force and temperature incline numerical outputs are tabulated contrary to stimulating physical objects. The uniqueness of the latest work is emphasized.

(1) The current study considers three-dimensional $\mathrm{CuO}+\mathrm{TiO}_{2} / \mathrm{C}_{2} \mathrm{H}_{6} \mathrm{O}_{2}$ hybrid nanofluid flow, while previous research $[38,39]$ has concentrated on viscous fluids and nanofluids.

(2) The MATLAB bvp4c algorithm has been used for the explanation of the non-linear problem.

(3) In comparison to other fluids, hybrid nanofluids have been found to increase the thermal efficiency of base fluids quickly.

\section{Mathematical Formulations}

To find another way to simplify the process of convection in fluids, the basis for this paper is a three-dimensional (3D) natural heat transfer of Newtonian two-phase nanofluid flow composed of $\mathrm{TiO}_{2} / \mathrm{CuO}$ hybrid particles/ethylene glycolwater (50 percent-50 percent) combination of base fluid due to a pivoting cone. All conclusions and conditions considered for the geometry of this paper are clearly shown in Figure 1. Differential equations that model the problem according to the assumptions mentioned above and the physical terms that affect the problem are

$$
\begin{gathered}
x \frac{\partial u}{\partial z}+u+x \frac{\partial w}{\partial z}=0 \\
\frac{\partial u}{\partial t}+u \frac{\partial u}{\partial x}-\frac{v^{2}}{x}+w \frac{\partial u}{\partial z}=-\frac{v_{e}^{2}}{x}+\frac{v_{h n f} \partial^{2} u}{\partial z^{2}}+g \zeta \cos \alpha^{*}\left(T-T_{\infty}\right),
\end{gathered}
$$




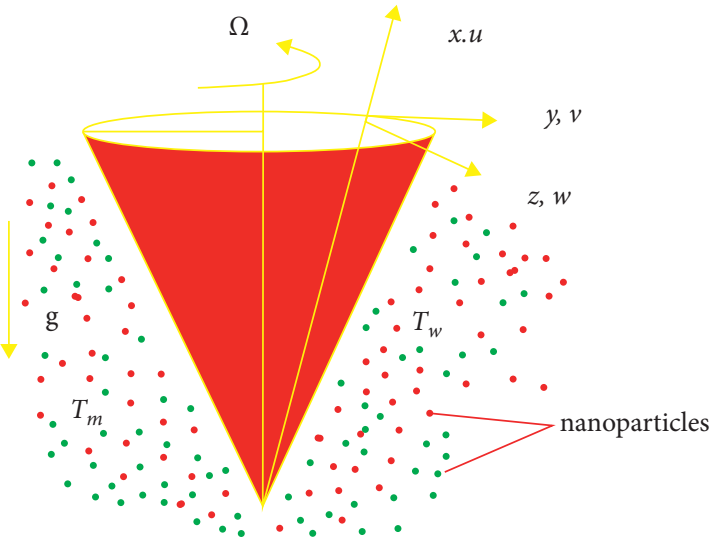

Figure 1: Corporeal geometry of the problem.

$$
\begin{gathered}
\frac{\partial v}{\partial t}+u \frac{\partial v}{\partial x}+u \frac{v}{x}+w \frac{\partial v}{\partial z}=\frac{\partial v_{e}}{\partial t}+v_{h n f} \frac{\partial^{2} v}{\partial z^{2}} \\
u \frac{\partial T}{\partial x}+w \frac{\partial T}{\partial z}+\frac{\partial T}{\partial t}=\alpha_{h n f} \frac{\partial^{2} T}{\partial z^{2}} .
\end{gathered}
$$

The velocity gears in the paths of $x, y$, and $z$-axis, separately, are in the above equations $(u, v$, and $w)$. Also, $\rho_{\text {hnf }}$ is the concentration of nanofluid, $\mu_{h n f}$ is the fluid viscosity of nanofluid, $v_{e}$ is the free flow velocity, $(\rho \beta)_{h n f}$ is the coefficient of growth and contraction because of the temperature difference, $T$ is the dynamic temperature, $\zeta$ is the electrical conductivity of the fluid, $\nu_{h n f}$ is kinematic viscosity, $\left(\rho C_{P}\right)_{h n f}$ is nanofluid's heat capacity, $k_{h n f}$ is nanofluid's heat conductivity, $A$ is the Deborah number, and $\alpha_{h n f}$ is the thermal diffusivity.

The boundary conditions are

$$
\begin{aligned}
u(0, x, z) & =v=w=u_{i}, v_{i} w_{i}, \\
T & =T_{i}, \\
u(t, 0, z) & =w=0, \\
v & =\frac{\Omega_{1} x \sin \alpha^{*}}{1-s t^{*}}, \\
T & =T_{W} .
\end{aligned}
$$

The momentum, temperature, and boundary conditions for this problem are $[38,39]$.

The most recent method would be the utilization of hybrid nanoparticles rather than single nanoparticles to advance the process of convection in fluids. Nanofluid formed by hybrid nanoparticles has higher conduction than nanofluid generated by one single nanoparticle. Furthermore, the impact of using nanoparticles of different shapes on conductivity and reducing the amount of convection cannot be simply overlooked.

Thermophysical Properties. The following are the different thermal properties of hybrid nanofluid and water [39]:

$$
\begin{aligned}
\rho_{h n f}= & {\left[\left(1-\phi_{2}\right)\left(1-\phi_{1}\right) \rho_{f}+\phi_{1} \rho_{c u o}\right]+\phi_{2} \rho_{\mathrm{Tio}_{2}}, } \\
\left(\rho C_{p}\right)_{h n f}= & {\left[\left(1-\phi_{2}\right)\left(1-\phi_{1}\right)\left(\rho c_{p}\right)_{f}+\phi_{1}\left(\rho c_{p}\right)_{c u o}\right] } \\
& +\phi_{2}\left(\rho c_{p}\right)_{T i o_{2}}, \\
\frac{k_{h n f}}{k_{n f}}= & \frac{k_{c u o}+2 k_{n f}-2 \phi_{1}\left(k_{n f}-k_{c u o}\right)}{k_{c u o}+2 k_{n f}+\phi_{1}\left(k_{n f}-k_{c u o}\right)}, \\
\frac{k_{n f}}{k_{f}}= & \frac{k_{T i o_{2}}+2 k_{n f}-2 \phi_{2}\left(k_{n f}-k_{\mathrm{Tio}_{2}}\right)}{k_{\mathrm{Tio}_{2}}+2 k_{n f}+\phi_{2}\left(k_{n f}-k_{\mathrm{Tio}_{2}}\right)} .
\end{aligned}
$$

Define the following transformation:

$$
\begin{aligned}
& \eta=\frac{\left(x \Omega \sin \alpha^{*}\right)^{0.5} z}{\nu\left(1-s t^{*}\right)^{0.5}}, \\
& v_{e}=\frac{x \Omega_{2} \sin \alpha^{*}}{1-s t^{*}}, \\
& \alpha=\frac{\Omega_{1}}{\Omega}, \\
& t^{*}=\Omega \sin \alpha^{*} t, \\
& w=\frac{\left(\sin \alpha^{*}\right)^{(1 / 2)}(\nu \Omega)^{(1 / 2)} f(\eta)}{\left(1-s t^{*}\right)^{(1 / 2)}} \\
& T-T_{\infty}=\left(T_{W}-T_{\infty}\right) \theta(\eta), \\
& u(t, x, z)=-\frac{2^{-1} \sin \alpha^{*} f^{\prime} \Omega x}{1-s t^{*}}, \\
& v=\Omega x \sin \alpha^{*}\left(1-s t^{*}\right)^{(1 / 2)} g(\eta), \\
& T_{W}-T_{\infty}=\frac{\left(T_{0}-T_{\infty}\right) x L^{-1}}{\left(1-s t^{*}\right)^{2}}, \\
& G r_{1}=\frac{\cos \alpha^{*}\left(T_{0}-T_{\infty}\right) g \beta L^{3}}{v^{2}}, \\
& \gamma_{1}=\frac{G r_{1}}{\operatorname{Re}_{L}^{2}}, \\
& \operatorname{Re}_{L}=\sin \alpha^{*} \Omega L^{2} v^{-1}, \\
& \operatorname{Pr}=\frac{\nu}{\alpha} .
\end{aligned}
$$

The functions required for the conversion of the partial differential equations (PDEs) ((2), (3), and (4)) to the ordinary differential equations (ODEs) are as follows.

In which the hybrid angular velocity is $\omega=\omega_{1}+\omega_{2}$, the angular velocities of a cone are $\omega_{1}$, the free torrent liquid is $\omega_{2}$, and the unstable parameter is $S$. Also, $\theta$ and $\zeta$ are the variable and temperature without dimensions, respectively. 
After substituting equation (7) into equations (2)-(4) and modifying and converting, the usual differential equations relating the flow and temperature, together with the boundary conditions, are as follows:

$$
\begin{gathered}
\left(\frac{f^{\prime \prime \prime}}{(1-\phi)^{2.5}\left(1-\phi_{2}\right)^{2.5}\left[\left(1-\phi_{2}\right)\left\{\left(1-\phi_{1}\right)-\phi_{1}\left(\rho_{\text {cuo }} / \rho_{f}\right)\right\}+\phi_{2}\left(\rho_{\text {Tio }} / \rho_{f}\right)\right]}-\left(f+\frac{1}{2} s \eta\right) f^{\prime}+\left(\frac{1}{2} f^{\prime}-s\right) f^{\prime}-2\left(g-\left(1-\alpha_{1}\right)^{2}\right)-2 \gamma_{1} \theta\right), \\
\left(\frac{g^{\prime \prime}}{(1-\phi)^{2.5}\left(1-\phi_{2}\right)^{2.5}\left[\left(1-\phi_{2}\right)\left\{\left(1-\phi_{1}\right)-\phi_{1}\left(\rho_{\text {cuo }} / \rho_{f}\right)\right\}+\phi_{2}\left(\rho_{\text {Tio }} / \rho_{f}\right)\right]}-\left(-f^{\prime} g+f g^{\prime}\right)+s\left(1-\alpha_{1}-g-\frac{1}{2} \eta g^{\prime}\right)\right), \\
\left(\frac{1}{\operatorname{Pr}}\left(\frac{\kappa_{h n f}}{\kappa_{f}}\right) \theta^{\prime \prime}-\left(f \theta^{\prime}-\frac{f^{\prime} \theta}{2}\right)-2 s \theta+\frac{1}{2} s \eta \theta^{\prime}\right) .
\end{gathered}
$$

Now, the boundary conditions are

$$
\begin{gathered}
f(0)=0, \\
g(\infty)=-1+\alpha_{1}, \\
g(0)=\alpha_{1}, \\
\theta(0)=-1, \\
f^{\prime}(\infty)=0, \\
f^{\prime}(0)=0, \\
\theta(\infty)=0 .
\end{gathered}
$$

The important natural quantities impacting the flow and the transfer of heat are the coefficient of skin friction $C_{f x}, C_{f y}$ and the local Nusselt number $N u_{x}$, respectively, which are clear as follows:

$$
\begin{aligned}
& C_{f x}=-\operatorname{Re}_{x}^{-(1 / 2)}\left(\frac{2 \mu \partial u}{\partial z}\right)_{z=0}, \\
& C_{f y}=\left(\frac{2 \mu \partial v}{\partial z}\right)_{z=0}\left(-\operatorname{Re}_{x}^{-(1 / 2)}\right) .
\end{aligned}
$$

Their dimensionless form is as follows:

$$
\begin{aligned}
& C_{f x} \operatorname{Re}_{x}^{(1 / 2)}=\left(\frac{1}{\left(1-\phi_{1}\right)^{2.5}\left(1-\phi_{2}\right)^{2.5}}\right)\left(-f^{\prime \prime}\right)_{\eta=0}, \\
& C_{f y} \operatorname{Re}_{x}^{(1 / 2)}=\left(\frac{1}{\left(1-\phi_{1}\right)\left(1-\phi_{2}\right)}\right)\left(-g^{\prime}\right)_{\eta=0} .
\end{aligned}
$$

The factor of heat allocation in dimensionless form is given as

$$
N u_{x} \operatorname{Re}_{x}^{(1 / 2)}=-\left(\frac{k_{h n f}}{k_{f}}\right) \theta^{\prime}(0) .
$$

\section{Numerical Solution}

The coupled ordinary, non-linear differential equations (8)-(10) and the limit conditions set out in equation (11) are numerically solved using the bvp4c MATLAB algorithm.

$$
\begin{aligned}
F & =y_{1}, \\
\rho_{f} & =b, \\
F^{\prime} & =y_{2}, \\
g & =y_{4}, \\
F^{\prime \prime} & =y_{3}, \\
\rho_{s} & =a, \\
g^{\prime} & =y_{5}, \\
g^{\prime \prime} & =y_{5}^{\prime}, \\
F^{\prime \prime} & =y_{3}^{\prime}, \\
\theta(0) & =y_{6}, \\
\theta^{\prime} & =y_{7}, \\
\theta^{\prime \prime} & =y_{7}^{\prime}, \\
k_{s} & =m, \\
k_{f} & =n, \\
\left(\rho c_{p}\right)_{s} & =c, \\
\left(\rho c_{p}\right)_{f} & =d .
\end{aligned}
$$

Now, the new equations are 


$$
\begin{aligned}
y_{3}^{\prime}= & {\left[\left[(1-\phi)^{2.5}\left(1-\phi_{2}\right)^{2.5}\left(1-\phi_{2}\right)\left(1-\phi_{1}\right)-\phi_{1}\left(\frac{a}{b}\right)+\phi_{2}\left(\frac{c}{b}\right)\right]\right.} \\
& \left.\cdot\left[\left(y(1) y(3)+\frac{1}{2} x s y(3)\right)-\frac{1}{2} y^{2}(2)+s y(2)\right)+2 y^{2}(4)-\left(1-\alpha_{1}\right)^{2}+2 \gamma_{1} y(6)\right], \\
y_{5}^{\prime}= & {\left[(1-\phi)^{2.5}\left(1-\phi_{2}\right)^{2.5}\left(1-\phi_{2}\right)\left(1-\phi_{1}\right)-\phi_{1}\left(\frac{a}{b}\right)+\phi_{2}\left(\frac{c}{b}\right)\right] } \\
& \cdot\left[y(1) y(5)-y(4) y(2)-s+s \alpha_{1}+s y(4)+\frac{1}{2} s x y(5)\right], \\
y_{7}^{\prime}= & {\left[\frac{(m+2)(n+2) \phi(n-m)}{(m+2)(n-2) \phi(n-m)}\right]\left[\operatorname{Pr} y(7) y(1)-\frac{y(6) y(2)}{2}\left(2 s y(6)-\frac{\operatorname{Pr} 1}{2} s x y(7)\right)\right], }
\end{aligned}
$$

along with limitation

$$
\begin{aligned}
y(1) & =0, \\
y_{\infty}(2) & =0, \\
y(2) & =0, \\
y(4) & =\alpha_{1}, \\
y(6) & =-1, \\
y_{\infty}(6) & =0 .
\end{aligned}
$$

\section{Graphical Observations and Discussion}

Non-linear standard differential equations (8)-(10) concerning boundary condition equation (11) are solved by the bvp4c method of numerical technique for evaluating the various physical parameters. Results indicate the effect on velocity $-f^{\prime}(\eta), g(\eta)$ and temperature $\theta(\eta)$ profiles of nondimensional governing parameters laterally with the skin friction constant and limited Nusselt number for recommended fence temperature (PWT) cases. We considered entirely dimensional parameter values for numerical algorithms as $s=2.0, \alpha_{1}=0.6, \phi=0.8, \gamma_{1}=1.5$, and $P r=7.0$. These parameter values are samein the entire article except for the disparities in the corresponding figures and tables. We learned that the heat transfer rate has been further increased due to hybrid nanofluid $\left(\mathrm{TiO}_{2}-\mathrm{Cuo}\right.$ /ethylene glycol-water). The rate of the heat transfer decreases when we increase the rotation parameter and the capacity fraction of nanoparticles. Figures 2-5 display the block diagram of the speed and temperature profiles for different models of the volume fractions of $\mathrm{Tio}_{2}$ and $\mathrm{Cuo}$ nanoparticles. The rise in the medium fraction of nanotubes augments the tangential velocity $-f^{\prime}(\eta)$ field and fluctuates the azimuthal velocity $g(\eta)$ field as well as the temperature profiles in the PWT case. As assumed, the improvement of the medium fraction of nanoparticles would enhance the colloidal interruption here amid solid particles, and due to this, the velocity fields are reduced. By contrast, the field of $\mathrm{TiO}_{2}$ nanoparticle velocity is faster by enhancing the values of the nanoparticle volume fraction. For this motive, we saw an enrichment in the field of tangential velocity. Figures 2(a) and 2(b) describe the effect of the $\alpha_{1}$ on prescribed wall temperature $(\mathrm{PWT})$ case velocity $-f^{\prime}$ profiles. The velocity curve decreases when increasing the values of $\alpha_{1}$ in $\mathrm{Cuo}-\mathrm{TiO}_{2}$ cases. In Figures 4(a) and 4(b), $\alpha_{1}$ indicates mixed solutions for both cases in fields of azimuthal velocity $g$. In both cases, velocity decreases if the value of this parameter increases. But with increasing values of $\alpha_{1}$ the tangential boundary layer of velocity $-f^{\prime}$ enables. Physically, the parameter of $\alpha_{1}$ helps to increase the velocity of the flow because for this reason the velocity fields are initially enhanced. At Figures 3(a) and 3(b) under the impact of the parameter $\gamma_{1}$ almost similar behavior is observed, but here the thickness of the boundary layer increases rapidly with the growth. Velocity behavior for $s$ the maximum value of s sluggish down the tangential speed of the fluid as well as velocity $-f^{\prime}$ goes to zero far absent from the cone superficial for high values of $s$ velocity profile goes down rdThe effects of the $\operatorname{Pr}$ on $\theta$ in both cases are shown in Figures 5(a) and 5(b). The depth of the thermal boundary layer and $\theta(\eta)$ increases by enhancing the values of Prandtl number Pr. The effect of the Reynolds number on tangential velocity is seen in Figures 5(a) and 5(b). It is represented in figures with an increase in $R e$ because inertial forces have a direct relationship with $R e$; The curve in Figure 6(a) increases and in 6(b) decreases with the increasing values of tangential velocities near the cone wall. Figures $7(\mathrm{a})$ and $7(\mathrm{~b})$ are devoted to the manifestation of the effect of $\gamma_{1}$ (buoyancy parameter) on the tangential skin friction coefficient. From these figures, it is clear that $C_{f x}$ grows as $\gamma_{1}$ increases, while it decreases as $\alpha_{1}$ increases. Figures $8(\mathrm{a})$ and $8(\mathrm{~b})$ indicate the impact on the skin friction coefficients $C_{f y}$ at the cone boundary of the rotation parameter $\left(\alpha_{1}\right)$ and Reynolds number. Skin friction coefficients are shown in figure 8(b) by increasing values of function of rotation parameters and $8(\mathrm{a})$ is decreasing by function of $\alpha_{1}$ while showing declining behavior for the number of Reynolds. The effect of $P r$ is shown in Figure 9(a) on the Nusselt number by an improvement in the value of $\mathrm{Pr}$ the Nusselt number decrease. From Figure 9(b), it is noted that the Nusselt number is decreased when enhancing the value of Pr. Tables 1 and 2 demonstrate the impact of several parameters on skin friction and Nusselt number for Reynolds model. Amount of $\alpha_{1}$ and $\gamma_{1}$ expand the skin and Nusselt number decline for $\alpha_{1}$ and grow for $\alpha_{1}$. Table 1 demonstrated the hybrid surface fluid and nanoparticles have fluid dynamics-physical properties 


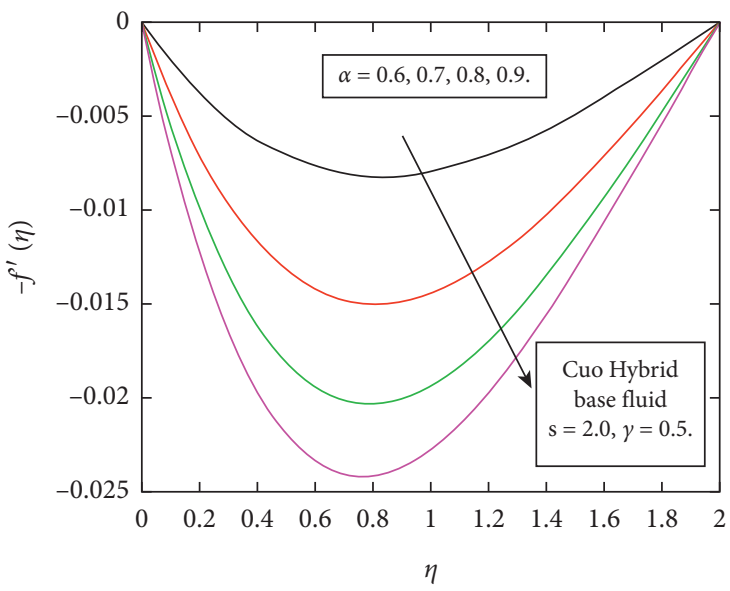

(a)

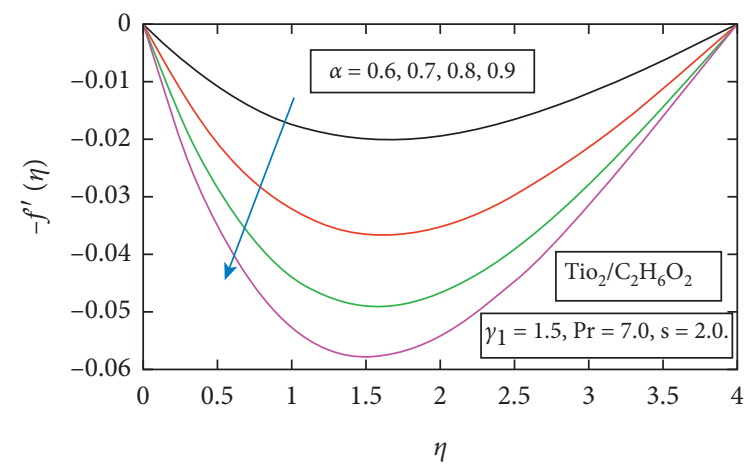

(b)

Figure 2: (a) Impact of $\alpha_{1}$ on the velocity field distribution $-f^{\prime}(\eta)$ for Cuo nanoparticles. (b) Impact of $\alpha_{1}$ on the velocity distribution $-f^{\prime}(\eta)$ for $\mathrm{TiO}_{2}$ nanoparticles.

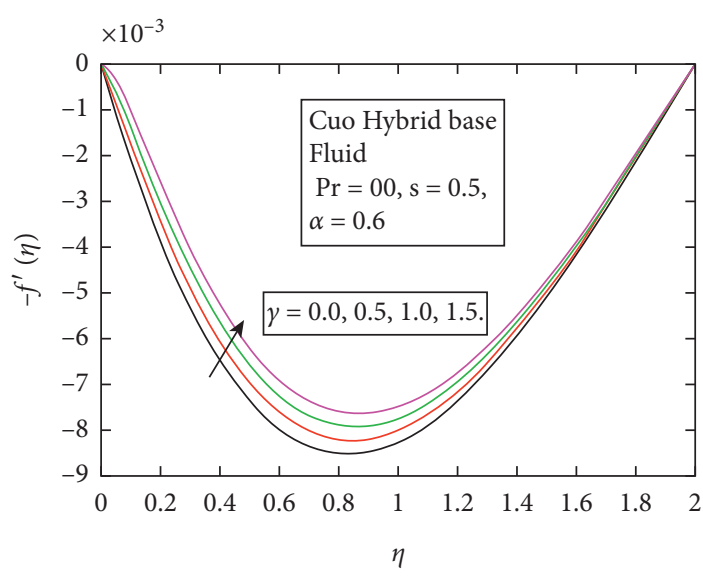

(a)

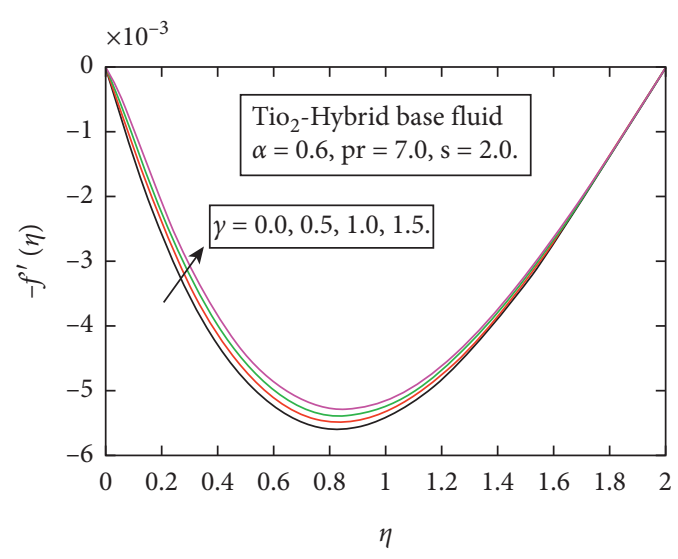

(b)

Figure 3: (a) Impact of $\gamma_{1}$ on velocity distribution $-f^{\prime}$ for Cuo nanoparticles. (b) Impact of $\gamma_{1}$ on velocity distribution $-f^{\prime}$ for TiO nanoparticles.

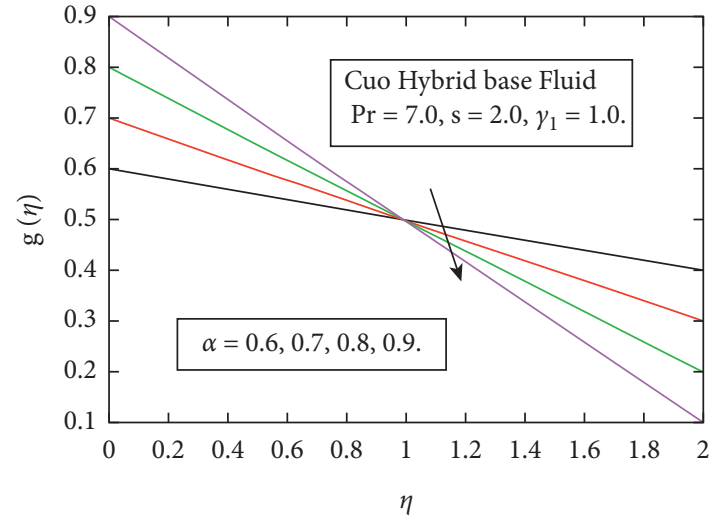

(a)

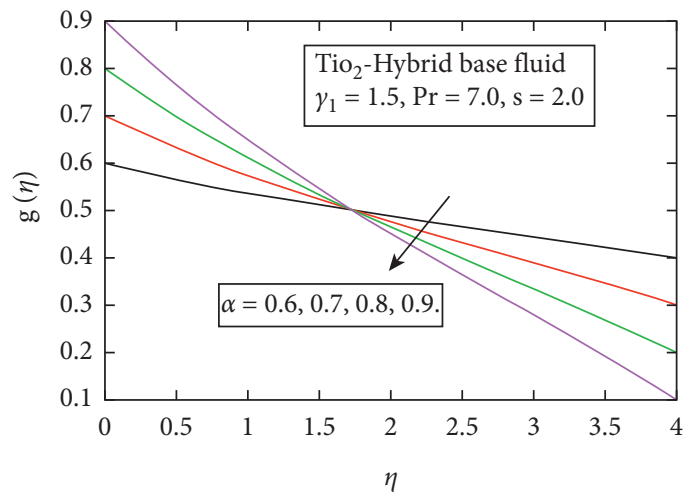

(b)

FIGURE 4: (a) Impact of $\alpha_{1}$ on velocity profile $g(\eta)$ for $\mathrm{CuO}$ nanoparticles. (b) Impact of $\alpha_{1}$ on velocity profile $g(\eta)$ for Tio 2 nanoparticles. 


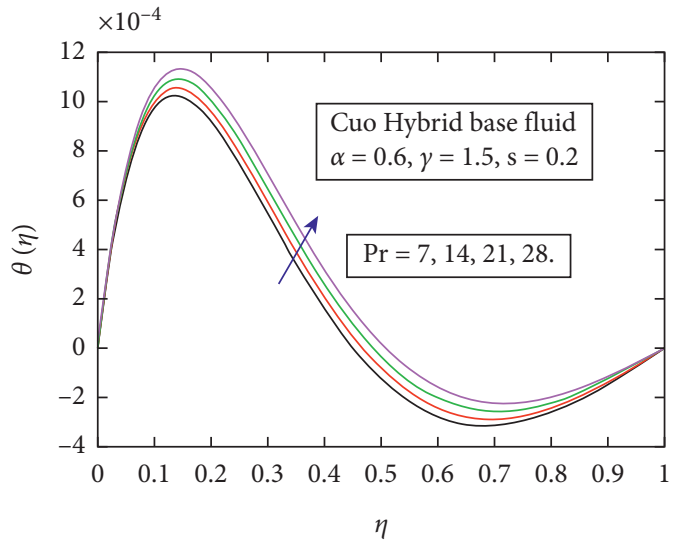

(a)

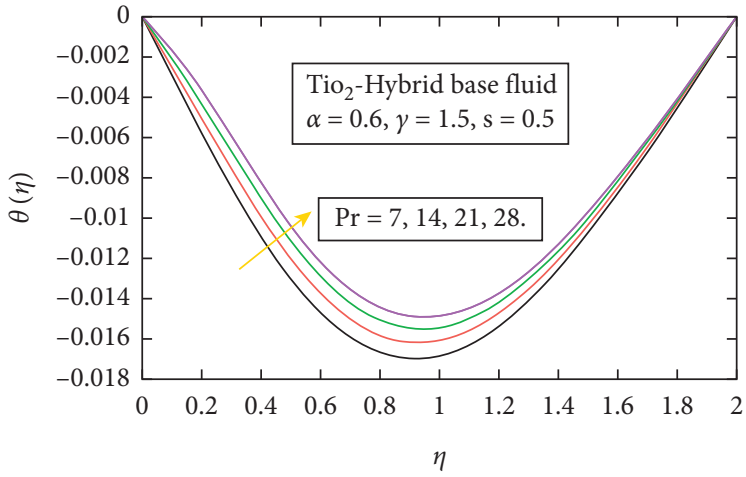

(b)

Figure 5: (a) Deviation of $\operatorname{Pr}$ on temperature profile $\theta(\eta)$ for $\mathrm{CuO}$ nanoparticles. (b) Deviation of $\operatorname{Pr}$ on temperature profile $\theta(\eta)$ for $\mathrm{TiO}_{2}$ nanoparticles.

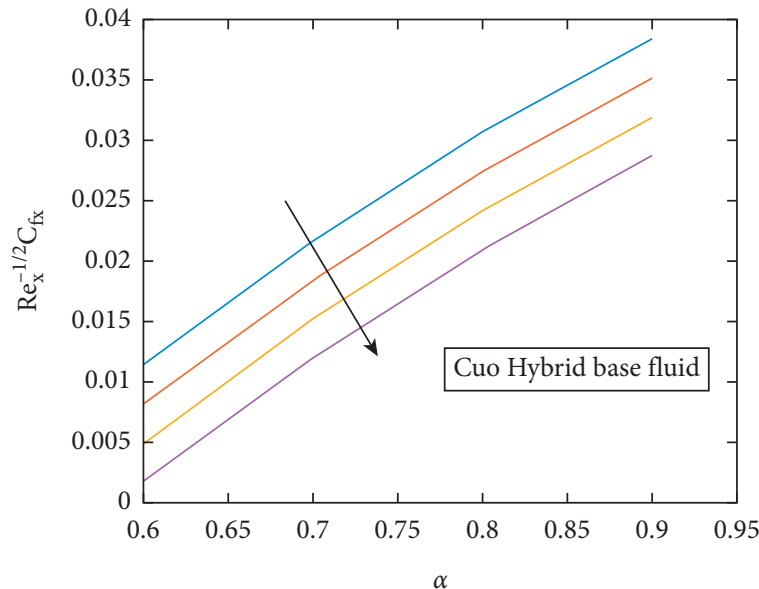

(a)

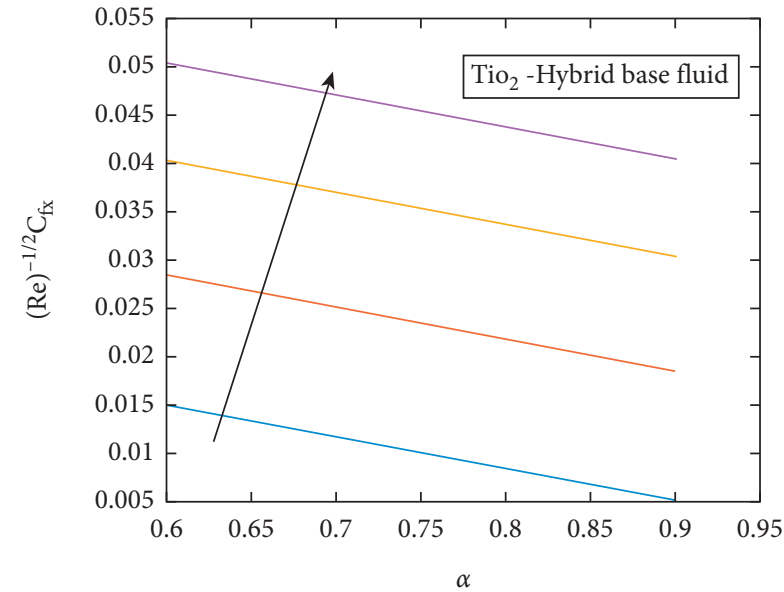

(b)

Figure 6: (a) Impact on skin friction $C_{f x}$ along $x$-direction with $\alpha_{1}$, for $\mathrm{CuO}$ nanoparticles. (b) Impact on skin friction $C_{f x}$ along $x$-direction with $\alpha_{1}$, for $\mathrm{TiO}_{2}$ nanoparticles.

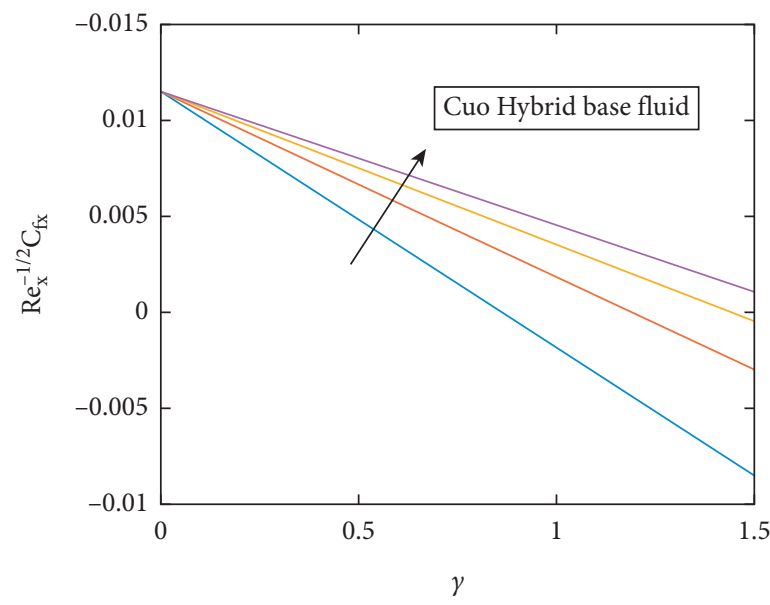

(a)

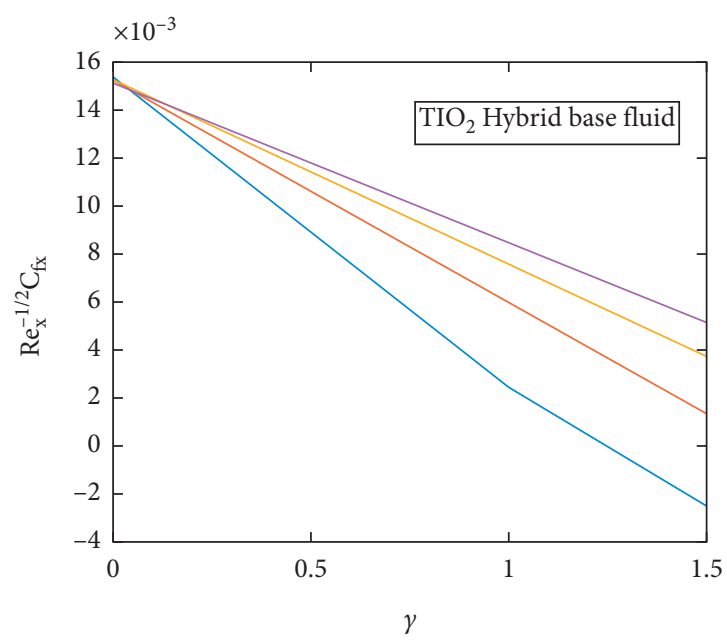

(b)

Figure 7: (a) Impact on skin friction of $\gamma_{1}$ along $x$-direction for $\mathrm{CuO}-\mathrm{C}_{2} \mathrm{H}_{6} \mathrm{O}_{2}$. (b) Impact on skin friction of $\gamma_{1}$ along $x$-direction for $\mathrm{TiO}_{2}-\mathrm{C}_{2} \mathrm{H}_{6} \mathrm{O}_{2}+$ water. 


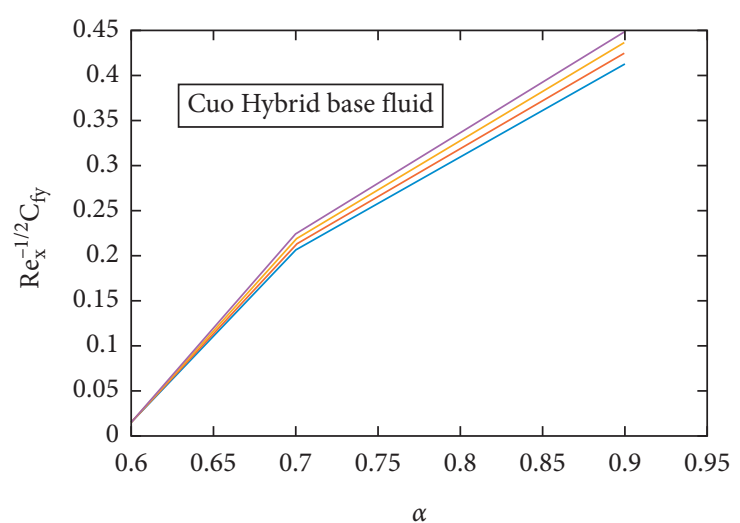

(a)

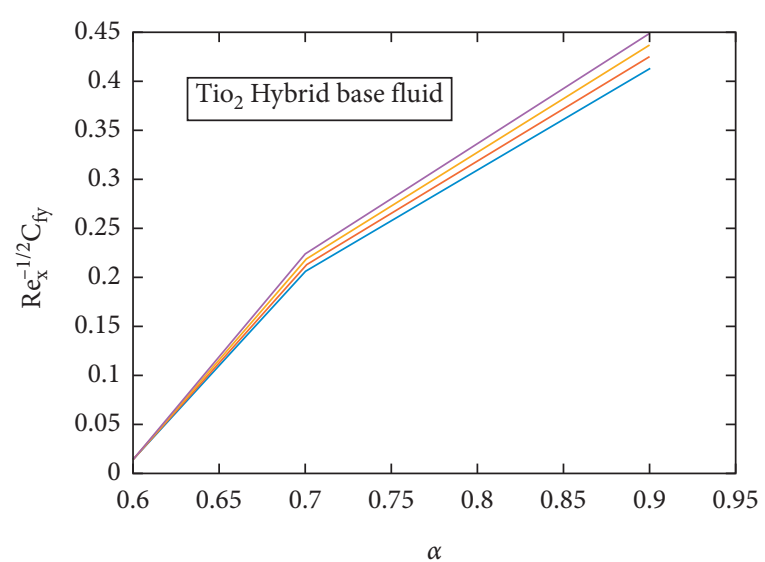

(b)

Figure 8: (a) Influence on skin friction $C_{f y}$ along $x$-direction of $\alpha_{1}$ for $\mathrm{CuO} / \mathrm{C}_{2} \mathrm{H}_{6} \mathrm{O}_{2}+$ water. (b) Influence on skin friction $\mathrm{C}_{f y}$ along $y$-direction of $\alpha_{1}$ for $\mathrm{TiO}_{2}-\mathrm{C}_{2} \mathrm{H}_{6} \mathrm{O}_{2}$.

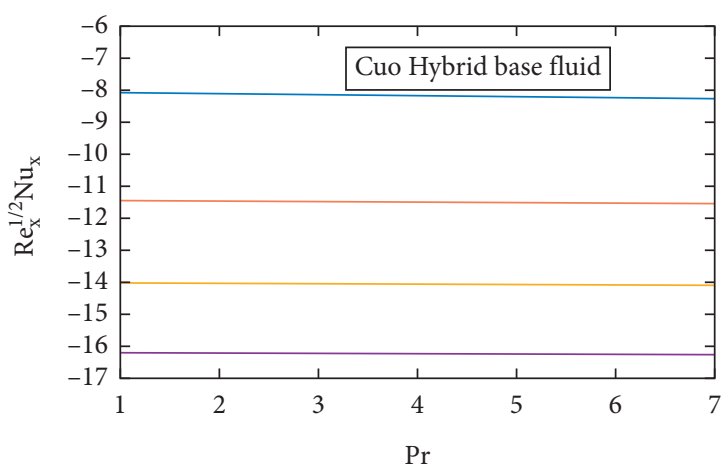

(a)

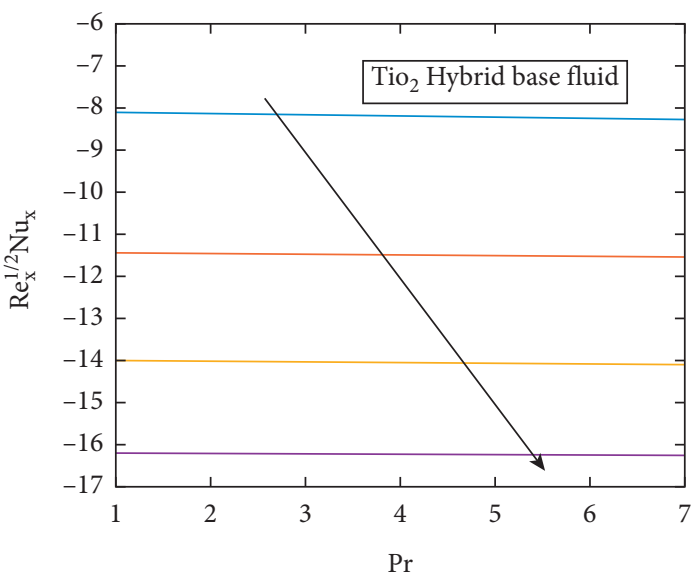

(b)

Figure 9: (a) Influence on Nusselt number of $\mathrm{Pr}$ for $\mathrm{CuO}-\mathrm{C}_{2} \mathrm{H}_{6} \mathrm{O}_{2}$. (b) Influence on Nusselt number of $\mathrm{Pr}$ for $\mathrm{TiO}_{2}-\mathrm{C}_{2} \mathrm{H}_{6} \mathrm{O}_{2}$.

TABLE 1: Impact of different parameters and dimensions of nanomaterials on velocity and temperature profiles in CuO-hybrid base fluid.

\begin{tabular}{|c|c|c|c|c|c|c|}
\hline$\alpha_{1}$ & $\gamma_{1}$ & $S$ & Pr & $\mathrm{C}_{\mathrm{fx}}$ & $C_{f y}$ & $\mathrm{Nu}_{\mathrm{x}}$ \\
\hline 0.6 & 0.5 & 1.0 & 7.0 & 0.01573 & 0.01530 & -5.01480 \\
\hline 0.7 & & & & 0.02965 & 0.00882 & -4.83310 \\
\hline 0.8 & & & & 0.04081 & 0.00202 & -4.45480 \\
\hline 0.9 & & & & 0.05035 & 0.00710 & -4.01480 \\
\hline \multirow[t]{3}{*}{0.7} & 0.0 & 2.0 & 5.0 & 0.01171 & 0.02283 & -7.24294 \\
\hline & 0.5 & & & 0.02535 & 0.01107 & -7.20510 \\
\hline & 1.0 & & & 0.03678 & 0.08875 & -7.16484 \\
\hline \multirow[t]{4}{*}{0.8} & 1.5 & 0.5 & 3.0 & 0.04706 & 0.00132 & -7.12153 \\
\hline & & 1.0 & & 0.00848 & 0.01523 & -8.89947 \\
\hline & & 1.5 & & 0.02186 & 0.01552 & -8.88430 \\
\hline & & 2.0 & & 0.03367 & 0.00754 & -8.86861 \\
\hline \multirow[t]{4}{*}{0.9} & 0.5 & 0.5 & 1.0 & 0.04379 & 0.00375 & -8.85267 \\
\hline & & & 3.0 & 0.00517 & 0.01573 & -10.2863 \\
\hline & & & 5.0 & 0.01849 & 0.01171 & -10.2791 \\
\hline & & & 7.0 & 0.03054 & 0.00898 & -10.2119 \\
\hline
\end{tabular}


TABLE 2: Results of skin friction and Nusselt coefficient for $\mathbf{T I O}_{2}$.

\begin{tabular}{|c|c|c|c|c|c|c|}
\hline$\alpha_{1}$ & $\gamma_{1}$ & $S$ & Pr & $\mathrm{C}_{\mathrm{fx}}$ & $C_{f y}$ & $\mathrm{Nu}_{\mathrm{x}}$ \\
\hline 0.6 & 0.5 & 1.0 & 7.0 & 0.01150 & 0.0114280 & -8.09597 \\
\hline 0.7 & & & & 0.00487 & 0.0216298 & -8.15971 \\
\hline 0.8 & & & & -0.00617 & 0.0306057 & -8.22153 \\
\hline 0.9 & & & & -0.04201 & 0.0383555 & -8.22153 \\
\hline \multirow[t]{3}{*}{0.7} & 0.0 & 2.0 & 5.0 & 0.01440 & 0.0049780 & -11.4494 \\
\hline & 0.5 & & & 0.00666 & 0.0151825 & -11.4824 \\
\hline & 1.0 & & & 0.00190 & 0.0241606 & -11.5149 \\
\hline \multirow[t]{4}{*}{0.8} & 1.5 & 0.5 & 3.0 & -0.00204 & 0.0319124 & -11.5471 \\
\hline & & 1.0 & & 0.01146 & 0.0082032 & -14.0226 \\
\hline & & 1.5 & & 0.00759 & 0.0184064 & -14.0448 \\
\hline & & 2.0 & & 0.00352 & 0.0273834 & -14.0448 \\
\hline \multirow[t]{4}{*}{0.9} & 0.5 & 0.5 & 1.0 & -0.00042 & 0.0351342 & -14.0669 \\
\hline & & & 3.0 & 0.01109 & 0.0017524 & -16.1919 \\
\hline & & & 5.0 & 0.00799 & 0.0119582 & -16.2087 \\
\hline & & & 7.0 & 0.00454 & 0.0209374 & -16.2253 \\
\hline
\end{tabular}

TABLE 3: The hybrid surface fluid and nanoparticles having fluid dynamic-physical properties.

\begin{tabular}{lccc}
\hline Physical Properties & $\mathbf{C u O}$ & $\mathbf{T i O}_{2}$ & $\mathbf{C}_{2} \mathbf{H}_{6} \mathbf{O}_{2}-\mathbf{H}_{2} \mathbf{O}$ \\
\hline$\rho\left(\mathrm{kg} / \mathrm{m}^{3}\right)$ & 6500 & 4250 & 1063.8 \\
$c_{p}(\mathrm{~J} / \mathrm{kgk})$ & 540 & 686.2 & 3630 \\
$K(w / m k)$ & 18 & 8.9538 & 0.387 \\
\hline
\end{tabular}

for Cuo and in Table 2 also shows the properties of $\mathrm{TiO}_{2}$. The thermophysical properties of the nanofluid are discussed in Table 3.

\section{Concluding Remarks}

In the present paper, the influence of rotation and buoyancy force parameters on velocity and temperature is discussed in hybrid base nanofluid over a gyrating cone in the occurrence of gravity and film condensation and heat dissipation effect. By using the bvp4c algorithm, we solve PDEs with minimum errors and correct results. The results indicate that by increasing the value of $\alpha_{1}$, the tangential and azimuthal velocity reduces near the boundary of the cone for $\mathrm{CuO}$ and $\mathrm{TiO} 2$ cases. Also, with the increase of $\gamma_{1}$, azimuthal velocity increases. The inclination of the Prandtl number results in an increase in the temperature profile. The skin friction factor is increasingby rotation and unstable parameters while it is decreasing with Reynolds number. The Nusselt number increases for larger $\operatorname{Pr}$ near the wall of the cone. The major outcomes of this study are given as follows:

(1) $\mathrm{TiO}_{2}$ nanofluid has a higher coefficient of friction factor as opposed to Cuo nanofluid. However, the heat transfer rate of $\mathrm{Tio}_{2}$ nanofluid is lower than that of Cuo nanofluid. Cuo nanofluid, therefore, improves the thermal transfer more than the $\mathrm{Tio}_{2}$ nanofluid.

(2) The parameter of viscous variation improves both temperature and the rate of heat transfer. Thus, we can say that viscosity dependent on temperature is helpful for processes of heat transfer modification.

(3) Hybridity reduces the velocity distribution while increasing the temperature distribution.
(4) As compared to nanofluid, hybrid nanofluid can have better heat transfer efficiency.

(5) The optimal heat transfer rate in hybrid nanofluid can be achieved by choosing distinct and sufficient nanoparticle increases.

(6) The heat source decreases the temperature field and enhances the heat transfer rate.
Abbreviations
Pr:
$t, t^{*}: \quad$ Dimensional and dimensionless times,
T: respectively
$\begin{array}{ll}T: & \text { Temperature } \\ (x, y, z): & \text { The distance measured along the meridian of }\end{array}$
$(x, y, z): \quad$ a circular segment parallel to the cone's superficial
$C_{f x}: \quad$ Local skin friction in $x$-direction
$\alpha: \quad$ Semi-upright angle of the cone
$C_{f y}: \quad$ Skin friction in $y$-direction
$\eta: \quad$ Similarity variable
$f, g: \quad$ Dimensionless stream function and velocity component in $x$ - and $y$-direction, respectively
$\theta: \quad$ Dimensionless temperature
$K, L: \quad$ Thermal conductivity and characteristic length, respectively
$K m^{-1} K^{-1} \gamma_{1}$ : Buoyancy parameter due to temperature
$\mu: \quad$ Dynamic viscosity $\left(\mathrm{Nms}^{-2}\right)$
$v$ : $\quad$ Kinematic viscosity $\left(\mathrm{m}^{2} \mathrm{~s}^{-1}\right)$
$N u_{x}: \quad$ Local Nusselt number
$\rho: \quad$ Density $\left(\mathrm{kgm}^{-3}\right)$
$R e_{x}$ : $\quad$ Reynold number based on $x$ 


$$
\begin{array}{ll}
R e_{L}: & \text { Reynold number based on } L \\
\left(\rho C_{p}\right)_{h n f}: & \text { Heat capacity of hybrid nanofluid }\left(j k^{-1}\right) \\
\rho_{h n f}: & \text { Nanofluid density }\left(\mathrm{kgm}^{-3}\right) \\
\mu_{f}: & \text { The viscosity of fluid }\left(\mathrm{Nms}^{-2}\right) \\
(u, v, w): & \text { Velocity components }\left(\mathrm{ms}^{-1}\right) \\
\mu_{h n f}: & \text { Hybrid nanofluid viscosity }\left(\mathrm{Nms}^{-2}\right) \\
\alpha_{h n f}: & \text { Hybrid nanofluid thermal diffusivity } \\
& \left(m^{2} s^{-1}\right) .
\end{array}
$$

\section{Data Availability}

The data used to support the findings of this study are available from the corresponding author upon request.

\section{Conflicts of Interest}

The authors declare that they have no conflicts of interest.

\section{Acknowledgments}

The authors extend their appreciation to the Deanship of Scientific Research at King Khalid University, Abha 61413, Saudi Arabia, for funding this work through the Research Groups Program under grant number R.G.P-1/88/42.

\section{References}

[1] E. Abd-Elaziz, M. Marin, and M. Othman, "On the effect of Thomson and initial stress in a thermo-porous elastic solid under G-N electromagnetic theory," Symmetry Plus, vol. 11, no. 3, p. 413, 2019.

[2] M. Y. Malik, A. Hussain, and S. Nadeem, "Flow of a nonNewtonian nanofluid between coaxial cylinders with variable viscosity," Zeitschrift für Naturforschung A, vol. 67, no. 5, pp. 255-261, 2012.

[3] R. Ellahi, M. Hassan, and A. Zeeshan, "Aggregation effects on water base Al2O3-nanofluid over permeable wedge in mixed convection," Asia-Pacific Journal of Chemical Engineering, vol. 11, no. 2, pp. 179-186, 2016.

[4] T. Salahuddin, M. Y. Malik, A. Hussain, M. Awais, I. Khan, and M. Khan, "Analysis of tangent hyperbolic nanofluid impinging on a stretching cylinder near the stagnation point," Results in Physics, vol. 7, pp. 426-434, 2017.

[5] R. Ellahi, M. Hassan, and A. Zeeshan, "A study of heat transfer in power law nanofluid," Thermal Science, vol. 20, no. 6, pp. 2015-2026, 2016.

[6] M. Khan, A. Shahid, M. Y. Malik, and T. Salahuddin, "Thermal and concentration diffusion in Jeffery nanofluid flow over an inclined stretching sheet: a generalized Fourier's and Fick's perspective," Journal of Molecular Liquids, vol. 251, pp. 7-14, 2018.

[7] A. Zeeshan, M. Hassan, R. Ellahi, and M. Nawaz, "Shape effect of nanosize particles in unsteady mixed convection flow of nanofluid over disk with entropy generation," Proceedings of the Institution of Mechanical Engineers - Part E: Journal of Process Mechanical Engineering, vol. 231, no. 4, pp. 871-879, 2017.

[8] R. Ellahi, M. Hassan, and A. Zeeshan, "Study of natural convection MHD nanofluid by means of single and multiwalled carbon nanotubes suspended in a salt-water solution," IEEE Transactions on Nanotechnology, vol. 14, no. 4, pp. 726-734, 2015.
[9] F. Ur Rehman, S. Nadeem, H. Ur Rehman, and R. Ul Haq, "Thermophysical analysis for three-dimensional MHD stagnation-point flow of nano-material influenced by an exponential stretching surface," Results in physics, vol. 8, pp. 316-323, 2018.

[10] D. Belatrache, N. Saifi, A. Harrouz, and S. Bentouba, "Modelling and Numerical Investigation of the thermal properties effect on the soil temperature in Adrar region," Algerian Journal of Renewable Energy and Sustainable Development, vol. 2, no. 02, pp. 165-174, 2020.

[11] R. Ali, A. Shahzad, M. Khan, and M. Ayub, "Analytic and numerical solutions for axisymmetric flow with partial slip," Engineering with Computers, vol. 32, no. 1, pp. 149-154, 2016.

[12] A. Shahzad, R. Ali, M. Hussain, and M. Kamran, "Unsteady axisymmetric flow and heat transfer over time-dependent radially stretching sheet," Alexandria Engineering Journal, vol. 56, no. 1, pp. 35-41, 2017.

[13] H. Chang, C. S. Jwo, C. H. Lo, T. T. Tsung, M. J. Kao, and H. M. Lin, "Rheology of $\mathrm{CuO}$ nanoparticle suspension prepared by ASNSS," Reviews on Advanced Materials Science, vol. 10, no. 2, pp. 128-132, 2005.

[14] A. K. Santra, S. Sen, and N. Chakraborty, "Study of heat transfer due to laminar flow of copper-water nanofluid through two isothermally heated parallel plates," International Journal of Thermal Sciences, vol. 48, no. 2, pp. 391-400, 2009.

[15] K. Das, P. R. Duari, and P. K. Kundu, "Nanofluid flow over an unsteady stretching surface in presence of thermal radiation," Alexandria engineering journal, vol. 53, no. 3, pp. 737-745, 2014.

[16] Y. Xuan and Q. Li, "Investigation on convective heat transfer and flow features of nanofluids," Journal of Heat Transfer, vol. 125, no. 1, pp. 151-155, 2003.

[17] M. Sheikholeslami, D. Domiri Ganji, M. Younus Javed, and R. Ellahi, "Effect of thermal radiation on magnetohydrodynamics nanofluid flow and heat transfer by means of two phase model," Journal of Magnetism and Magnetic Materials, vol. 374, pp. 36-43, 2015.

[18] M. Sheikholeslami Kandelousi, "KKL correlation for simulation of nanofluid flow and heat transfer in a permeable channel," Physics Letters A, vol. 378, no. 45, pp. 3331-3339, 2014.

[19] M. Sheikholeslami and A. J. Chamkha, "Flow and convective heat transfer of a ferro-nanofluid in a double-sided lid-driven cavity with a wavy wall in the presence of a variable magnetic field," Numerical Heat Transfer, Part A: Applications, vol. 69, no. 10, pp. 1186-1200, 2016.

[20] M. Sheikholeslami and A. J. Chamkha, "Electrohydrodynamic free convection heat transfer of a nanofluid in a semi-annulus enclosure with a sinusoidal wall," Numerical Heat Transfer, Part A: Applications, vol. 69, no. 7, pp. 781-793, 2016.

[21] M. Sheikholeslami and A. J. Chamkha, "Influence of Lorentz forces on nanofluid forced convection considering Marangoni convection," Journal of Molecular Liquids, vol. 225, pp. 750757, 2017.

[22] S. Vlase, M. Marin, A. Öchsner, and M. L. Scutaru, "Motion equation for a flexible one-dimensional element used in the dynamical analysis of a multibody system," Continuum Mechanics and Thermodynamics, vol. 31, no. 3, pp. 715-724, 2019.

[23] M. Y. Malik, "Effects of second order chemical reaction on MHD free convection dissipative fluid flow past an inclined porous surface by way of heat generation: a Lie group analysis," Information Sciences Letters, vol. 5, no. 2, p. 1, 2016.

[24] R. Sivaraj and B. Rushi Kumar, "Viscoelastic fluid flow over a moving vertical cone and flat plate with variable electric 
conductivity," International Journal of Heat and Mass Transfer, vol. 61, pp. 119-128, 2013.

[25] A. Hussain, A. Rehman, S. Nadeem et al., "A combined convection carreau-yasuda nanofluid model over a convective heated surface near a stagnation point: a numerical study," Mathematical Problems in Engineering, vol. 2021, Article ID 6665743, 14 pages, 2021.

[26] W. A. Aissa and A. A. Mohammadein, "Joule heating effects on a micropolar fluid past a stretching sheet with variable electric conductivity," Journal of Computational and Applied Mechanics, vol. 6, no. 1, pp. 3-13, 2005.

[27] M. M. Rahman, M. J. Uddin, and A. Aziz, "Effects of variable electric conductivity and non-uniform heat source (or sink)on convective micropolar fluid flow along an inclined flat plate with surfaceheat flux," International Journal of Thermal Sciences, vol. 48, no. 12, pp. 2331-2340, 2009.

[28] M. M. Rahman, A. Aziz, and M. A. Al-Lawatia, "Heat transfer in micropolar fluid along an inclined permeable plate with variable fluid properties," International Journal of Thermal Sciences, vol. 49, no. 6, pp. 993-1002, 2010.

[29] C. J. Chrisman, P. Albuquerque, A. J. Guimaraes, E. Nieves, and A. Casadevall, "Phospholipids trigger Cryptococcus neoformans capsular enlargement during interactions with amoebae and macrophages," PLoS Pathogens, vol. 7, no. 5, Article ID e1002047, 2011.

[30] S. Z. Shirejini, S. Rashidi, and J. A. Esfahani, "Recovery of drop in heat transfer rate for a rotating system by nanofluids," Journal of Molecular Liquids, vol. 220, pp. 961-969, 2016.

[31] M. Turkyilmazoglu, "Effects of uniform radial electric field on the MHD heat and fluid flow due to a rotating disk," International Journal of Engineering Science, vol. 51, pp. 233-240, 2012.

[32] M. Turkyilmazoglu, "Fluid flow and heat transfer over a rotating and vertically moving disk," Physics of Fluids, vol. 30, no. 6, Article ID 063605, 2018.

[33] M. Turkyilmazoglu, "A note on the induced flow and heat transfer due to a deforming cone rotating in a quiescent fluid," Journal of Heat Transfer, vol. 140, no. 12, 2018.

[34] R. Kumar, G. S. Seth, and A. Bhattacharyya, "Entropy generation of von Karman's radiative flow with $\mathrm{Al} 2 \mathrm{O} 3$ and $\mathrm{Cu}$ nanoparticles between two coaxial rotating disks: a finiteelement analysis," The European Physical Journal Plus, vol. 134, no. 12, pp. 1-20, 2019.

[35] M. Turkyilmazoglu, "On the fluid flow and heat transfer between a cone and a disk both stationary or rotating," Mathematics and Computers in Simulation, vol. 177, pp. 329-340, 2020.

[36] T. Gul, R. S. Gul, W. Noman et al., "CNTs-Nanofluid flow in a Rotating system between the gap of a disk and cone," Physica Scripta, vol. 95, no. 12, Article ID 125202, 2020.

[37] L. A. Lund, Z. Omar, J. Raza, and I. Khan, "Magnetohydrodynamic flow of $\mathrm{Cu}-\mathrm{Fe} 3 \mathrm{O} 4 / \mathrm{H} 2 \mathrm{O}$ hybrid nanofluid with effect of viscous dissipation: dual similarity solutions," Journal of Thermal Analysis and Calorimetry, vol. 143, no. 2, pp. 915-927, 2021.

[38] P. K. Kameswaran, P. Sibanda, C. RamReddy, and P. V. Murthy, "Dual solutions of stagnation-point flow of a nanofluid over a stretching surface," Boundary Value Problems, vol. 10, no. 1, pp. 1-12, 2013.

[39] S. U. Devi and S. A. Devi, "Heat transfer enhancement of $\mathrm{Cu}-\mathrm{Al} 2 \mathrm{O} 3 /$ water hybrid nanofluid flow over a stretching sheet," Journal of the Nigerian Mathematical Society, vol. 36, no. 2, pp. 419-433, 2017. 